\title{
Disabling barriers experienced by students with disabilities in postsecondary introductory physics
}

\author{
Westley James \\ Physics Department, University of Central Florida, Orlando, Florida 32816, USA \\ Caroline Bustamante, Kamryn Lamons, Erin Scanlon, and Jacquelyn J. Chini®)* \\ Physics Department, University of Central Florida, Orlando, Florida 32816, USA
}

(Received 28 February 2020; accepted 16 July 2020; published 19 August 2020)

\begin{abstract}
Educators and education researchers in postsecondary physics have rarely centered (i.e., intentionally directed attention to) the experiences of students with disabilities, leading to an instructional environment that is not designed to support students with disabilities. In this study, we interviewed five students who identified with the diagnosis of attention-deficit/hyperactivity disorder (ADHD) and were enrolled in introductory physics courses at a public four-year institution. We framed our investigation with a social relational perspective of disability, which posits that an individual's impairments (referred to as diagnosis characteristics in this paper) interact with social structures to result in disabling barriers (i.e., characteristics of social structures which prevent equal access for individuals with disabilities). We analyzed interview transcripts with interpretative phenomenological analysis (IPA). We found that the participating students discussed diagnosis characteristics including difficulties with focus, being prone to distractions, difficulties with keeping mental track of tasks and structures, and thinking often about abstract concepts. Diagnosis characteristics identified as challenges could result in negative selfperceptions, possibly as a result of internalized ableism. However, students also expressed that understanding their diagnosis led to benefits such as making more informed choices about their study strategies (e.g., using a planner or chunking their studying time). In alignment with our social relational perspective of disability, we found that course design could support or hinder participants' ability to use their preferred planning or studying strategies. We also found that students experienced increased barriers in their physics courses compared to other courses, specifically due to the increased time needed to process information and a lack of guidance for how to effectively study content for conceptual understanding. SCALE-UP courses introduced supports due to increased student autonomy but could also introduce barriers due to increased distractions. We present recommendations that instructors can implement to increase course supports. Researchers need to continue to center the experiences of students with disabilities in STEM courses so that researchers and practitioners can identify disciplinarily specific strategies to support student engagement and learning.
\end{abstract}

DOI: 10.1103/PhysRevPhysEducRes.16.020111

\section{INTRODUCTION}

Students with disabilities make up a significant portion of postsecondary students and enroll in science, technology, engineering, and math (STEM) courses at equivalent or higher rates than their peers depending on the type of institution [1,2]. However, previous work has identified that curricula for introductory physics courses have not

\footnotetext{
jchini@ucf.edu
}

Published by the American Physical Society under the terms of the Creative Commons Attribution 4.0 International license. Further distribution of this work must maintain attribution to the author(s) and the published article's title, journal citation, and DOI. been designed to support students with disabilities [3] and postsecondary instructors across all disciplines lack knowledge about how to support students with disabilities [4-6], even though United States laws prohibit discrimination against students with disabilities and mandate equitable access to course materials $[7,8]$.

Using a social relational perspective of disability, we posit that course structures interact with an individual's diagnosis characteristics to result in disabling barriers for students with disabilities [9]. Disabling barriers are defined as characteristics of social structures which disable individuals with disabilities from access to and participation in social structures; in this study the disabling barriers of interest are primarily related to course design [10]. However, there is a significant lack of research investigating the experiences of students with 
disabilities in postsecondary physics courses. To add to this knowledge base, we investigated the experiences of students with attention-deficit/hyperactivity disorder (ADHD) in introductory physics courses at a single institution. We interviewed students with ADHD to explore how they understood their diagnosis, i.e., diagnosis characteristics, and the practices they implemented to succeed in postsecondary courses. By identifying this information, we were able to distinguish how physics courses interacted with participants' diagnosis characteristics and implemented practices to result in supportive or disabling experiences. From students' experiences, we recommend practices and strategies instructors can implement to increase support for students with ADHD, especially in introductory physics courses.

Next, we present several models of disability, including the social relational perspective that we used in this study. Following this we describe the representation of students with disabilities in postsecondary STEM. We also summarize the legislative requirements for postsecondary institutions along with the research on accommodation use, postsecondary instructors' knowledge about students with disabilities, and the experiences of postsecondary students with disabilities in STEM courses.

\section{A. Models of disability}

Disability can be conceptualized through different models. Models of disability vary in where they position the source of disability (e.g., within the individual versus within social structures), which impacts the framing of response to challenges experienced by people with disabilities. People who are able-bodied (i.e., do not identify with a disability) often hold a medical model perspective of disability [11]. In this model, disability is described as a consequence of a personal, functional limitation (i.e., impairment to be "cured" or "fixed") [12]. Byproducts of the medical model include medication or technologies which have been developed in response to "limitations." Alternately, many people in the disability rights movement hold beliefs aligned with the social model of disability [13]. The social model situates disability within social constructs rather than within the individual. Social constructs are things made by people for people (e.g., manmade structures, learning environments, media). Applying the social model, Goodley [12] states that "social, cultural, historical, economic, relational, and political factors disable individuals" and that "disabled individuals" can be given access through the reduction of social barriers (p. 9). While there are other perspectives of disability, the medical and social models have been driving forces in modern Western industrialized societies' social structures and legislation and are relevant to our context; different models may be more relevant in other contexts, such as the Global South [14].

\section{B. Model of disability employed in this study: Social relational perspective}

In this study, we applied the social relational perspective of disability, a particular take on the social model that emphasizes the relationship between impairment and disabling social structures [9]. Under this model, Thomas [9] defines disability as "...social exclusion on the grounds of impairment" (p. 15) and impairment as “... the embodied sociobiological substance-socially marked as unacceptable bodily deviation - that mediates the social relationships in question" (p. 15). Thomas posits that while impairments have a biological source (i.e., they are not caused by social structures), impairments are socially understood (i.e., they are identified and understood through comparison to others).

The social relational perspective acknowledges that impairments shape individuals' experiences. Thomas [9] argues for the inclusion of this perspective of impairment in the social model, which traditionally ignores personal characteristics (i.e., impairments) and only focuses on social structures. While the social relational perspective maintains the social model stance that social structures create barriers that disable people, it also defines "impairment effects" as other limitations a person may experience due to their impairment that cannot be remediated by social change. Thomas demonstrates the difference between impairment effects and disability with a personal example: "the fact that I cannot hold a spoon or a saucepan in my left hand is an effect of my impairment and does not constitute disability in the social relational sense." [15] (p. 43).

In place of Thomas's impairment effects, we use the term "diagnosis characteristics" to make space for the limiting and/or negative characteristics individuals associate with their diagnosis as well as positive byproducts that individuals associate with their diagnosis. Diagnosis characteristics better aligns with the affirmative model of disability, which posits ".... a non-tragic view of disability and impairment which encompasses positive social identities, both individual and collective..." [16] (p. 569). For example, Swain and French describe that disabled individual's impairments may lead them to have increased empathy for others in oppressive situations [16].

Our adoption of the social relational perspective has two significant effects on this study. First, we identified disabling course structures based on students' perceptions of the interactions between their diagnosis characteristics and course structures that resulted in barriers or provided supports. Thus, we had to investigate student's diagnosis characteristics in order to identify when students experienced course structures that interacted with those diagnosis characteristics. Second, we targeted our recommendations at the course structure level since instructors and institutions have the agency to adjust course structures to reduce barriers and support access. 


\section{Students with disabilities in postsecondary education}

Students with disabilities ${ }^{1}$ comprise $10 \%-20 \%$ of the college student population $[18,19]$, and it is estimated that between $20 \%$ and $30 \%$ of students with disabilities have a specific diagnosis of an attention disorder (e.g., ADHD) ${ }^{2}$ [21]. Thus, approximately $2 \%-6 \%$ of college students identify with ADHD. Additionally, in $201510.5 \%$ of students enrolled in science and engineering degree programs were students with disabilities [18], and Lee [2] found that students with disabilities are just as likely to enroll in STEM degree programs as students without disabilities. At two year institutions, students with disabilities were more likely to choose STEM majors than students without disabilities [2].

\section{Existing supports for students with disabilities provided in college}

Both accommodations and inclusive practices can provide support for students with disabilities in college. Inclusive practices provide multiple routes for students to engage, supporting engagement by students with a variety of needs, abilities, and interests [22]. On the other hand, accommodations are extra supports provided to individual students, often by an institution's disability services office (DSO), to provide students with disabilities similar access to the course as other students. For example, a student with ADHD may receive a quiet testing environment as an accommodation because typical classroom noises affect their concentration and ability to demonstrate their understanding of course material. Accommodations are legally mandated based on requirements stating that if equal access is not possible within existing environments, then an institution must "provide appropriate academic adjustments as necessary to ensure that it does not discriminate on the basis of disability" (e.g. extra test time, note taking services, and interpreters) [23]. The legislative requirements for $\mathrm{K}-12$ are more extensive and include the responsibility to identify and diagnose students with no additional cost to families. Once a student is diagnosed, the school is responsible for the development of an individual education plan (IEP) for the student, which outlines when learning goals will be achieved and the supports that will be provided to ensure the goals are achieved [24]. Thus, students transitioning from $\mathrm{K}-12$ to postsecondary settings may encounter a significant reduction in supports.

\footnotetext{
${ }^{1}$ The statistics for the postsecondary enrollment of students with disabilities vary due to different methods of data collection, specifically in definitions of disability categories and identification of disabilities [4,17].

${ }^{2}$ This data source lists the diagnoses of ADHD and attention deficit disorder (ADD). However, the use of ADD was removed in Diagnostic Statistical Manual (DSM)-III-R, a manual for diagnosing individuals with disabilities [20], so we will only use ADHD.
}

Students with disabilities have reported that accommodations are critical for their success [25-27]. Ofiesh et al. [27] found that extra test time was particularly beneficial for students with ADHD as it gave students the time to focus and take a break if necessary. While many instructors are aware of the obligation to provide accommodations, there is significant variation in their familiarity with legislation related to accessibility in postsecondary education [28-30]. This can result in some instructors not providing or allowing the use of accommodations, even though there is a legal requirement to do so $[28,31,32]$. Additional barriers to receiving accommodations include the requirements for a formal disability diagnosis to receive accommodation services and a lack of student awareness regarding the services available to them. Students may also opt to not use accommodations due to desires to be selfsufficient and address their needs on their own $[31,33]$ or fears of disability stigma (e.g., that professors or peers will view them differently or negatively because of their disability diagnosis) $[32,34,35]$. Thus, while postsecondary institutions are required to provide accommodations, students may not use them.

As facilitators of learning, instructors can increase or decrease the support for learner variation in their courses based on how they have students receive, engage with, and express understanding of content [36]. However, postsecondary instructors lack knowledge of how to support students with disabilities in their courses [4-6] and often come into teaching with little to no experience related to supporting students with disabilities [37]. Few STEM instructors have received training in teaching [38], let alone training related to supporting students with disabilities [39], and often only learn to support students with disabilities through prolonged teaching and interaction with them in their courses $[40,41]$. The effect is that students report that instructors lack familiarity in working with [35,42] and know little about [4] students with disabilities.

\section{E. There is a lack of research about the experiences of students with disabilities in STEM courses}

Significant work has been done to investigate the experiences and perspectives of students with ADHD in postsecondary environments $[26,43,44]$. However, these findings are not specific to any course or discipline. Student experiences vary based on context, and physics courses present new challenges for many students [45].

Recent research has begun to investigate the accessibility of physics departments [46] and curriculum [3], and multiple studies have problematized and addressed barriers experienced in physics labs for individuals with auditory or visual impairments [47-49]. However, little work has investigated the specific experiences of students with nonapparent disabilities in physics courses. Impairments 
like ADHD, learning disabilities, autism spectrum disorder, and anxiety are sometimes called invisible, hidden, or nonapparent disabilities because they do not carry a physical marker and may not be apparent to outside observers. Social movements focusing on the rights of individuals with disabilities [11] have demonstrated the importance of centering people with disabilities in exploring their experiences, identifying supports and barriers, and designing solutions [50]. Previous research has also shown that centering people with disabilities is effective in improving how STEM instructors [40] and departments [51] support students with disabilities. In our context, we define centering to mean the intentional attentiveness to the experiences and perspectives of a group of people. Kerschbaum and Price explain "centering disability involves turning to disabled people's lived experiences to generate transformational knowledge that can contribute to more equitable practices" (pg. 98). Centering is especially important for populations that have been traditionally marginalized and underinvestigated, such as individuals with disabilities [52].

To summarize, students with disabilities enroll in postsecondary physics courses, however, little work has investigated whether the existing course structures support or hinder students with disabilities. Though there is a legal requirement to ensure courses are accessible for students with disabilities, instructors lack awareness of how to support students with disabilities and physics courses and content are not designed with this population in mind. The consequence is that students with disabilities encounter disabling course practices which inhibit equal access to engaging with physics courses. By interviewing students with disabilities about their experiences in postsecondary physics courses, we identified existing barriers in physics courses and suggest strategies and practices which can make physics courses more inclusive.

\section{RESEARCH QUESTIONS}

Because of the lack of knowledge about the experiences of students with disabilities in postsecondary STEM, we investigated students' experiences in postsecondary STEM courses. We specifically sought to investigate what disabling or supportive experiences students with disabilities had in STEM courses due to interactions between diagnosis characteristics and course structures (i.e., aligned with the social relational perspective), which also led to participants describing their views of their diagnosis characteristics.

1. What diagnosis characteristics do students with ADHD associate with their diagnosis, and how do students view these diagnosis characteristics?

2. What course structures interact with students' diagnosis characteristics to support or disable students with ADHD in physics and nonphysics courses?

\section{METHODS}

We chose to collect data through individual interviews to provide depth versus generalization of findings. In this section we describe our analytic framework, interpretative phenomenological analysis, and the positionality of our research team. Next, we discuss our recruitment of students with ADHD. We also outline the analysis procedure and steps taken to increase the trustworthiness of our interpretations of participants' experiences.

\section{A. Analytic framework}

We analyzed the interview transcripts generated in this study with interpretative phenomenological analysis (IPA) because this framework acknowledges that we are researchers interpreting the lived experiences of others [53]. IPA follows a hermeneutic theory and methodology, which proposes that to investigate an individual's lived experiences, the investigator must interpret the words and mindset of the individual in question [54]. In IPA, this interpretation process is acknowledged as having two levels: the researcher is making sense of participants who are making sense of their experiences. The researcher also has the capacity to make connections participants may be unaware of, such as across participants' experiences or in relation to previous research [53]. Because of the focus on the detail and breadth of experiences of each participant, Smith and Osborn recommend small sample sizes; they suggest six participants for researchers new to using IPA [53].

We selected this methodology because it respects the unique perspective each participant holds towards disability. At the same time, IPA acknowledges the researchers' roles as active interpreters, which was critical in this study as we needed to actively interpret participant's responses throughout analysis to identify course structures that interacted with participant's diagnosis characteristics. We also recognized that significant work has been done regarding disability, and IPA supports the use of this previous work as a rich lens to contextualize our findings.

\section{B. Positionality}

In this section we document the backgrounds of the researchers involved in analysis and how we chose to respond to, or take into account, these backgrounds in our interpretative phenomenological analysis of participants' experiences. Since we are active interpreters of the data, our identities, background knowledge, and experiences will affect the interpretations we generate. By acknowledging our identities, we can better account for how they may affect our interpretations of data $[55,56]$. Three researchers (W. J., K. L., and C. B.) worked collaboratively during analysis. Our research team represented a range of disability identities, including nondisabled, diagnosed with ADHD, and undiagnosed but identifying with diagnosis characteristics associated with ADHD. One of us was a 
graduate student (W. J.) and the others were undergraduate students (K. L., C. B.). We come from a variety of disciplinary backgrounds, including physics and nonphysics backgrounds.

The IPA framework emphasizes a "participant-oriented" analysis and therefore recommends researchers bracket (i.e., set aside) their experiences or perspectives when interpreting participants' interpretations of experiences $[53,57]$. However, researchers may be unaware of when they are bringing personal experiences or perspectives into the interpretation. In alignment with the IPA framework, we aimed to have interpretations be based on what participants intended to express rather than what we researchers have experienced. By intentionally forming a research team from a variety of backgrounds, we sought to provide external checks (i.e., other researchers) who could identify when a researcher's personal experiences or perspectives regarding disability were leading to interpretations that went beyond what participants intended to express [58].

We highly valued including researchers who were students and who identified with a disability, as we believed they were well equipped for this analysis due to their intimate familiarity with how course structures can support or disable them due to interactions with diagnosis characteristics. However, we still did not want to assume that participants' experiences regarding ADHD and course structures were the same as researchers' experiences regarding ADHD and course structures. Therefore, though one researcher did identify with $\mathrm{ADHD}$, we did not give increased weight to their interpretations since we did not want to assume the experiences of participants were the same as this researcher's experiences. We sought to give equal value to each researchers' perspectives to support aligning our interpretations with the experiences participants intended to express.

\section{Participants, context, and data collection}

Participants were recruited from introductory physics and chemistry courses at a large southeastern researchintensive university. Recruitment was done through emails which the university's disability service office sent on our behalf to students registered with their office. We also requested that the course instructors send this email to all students to recruit students who identified with a disability but had not registered with the disability service office, and we contacted students who confirmed that they identified with a disability. Participants took part in one-hour long semistructured interviews at the beginning and end of the semester. The interviews focused on the student's experiences in their college courses, with an emphasis on their STEM courses and how their diagnosis interacted with their college experiences. A limitation of the interview protocol is that it was not intentionally designed to have participants explicitly identify diagnosis characteristics. There were only two questions with specific prompts regarding how
TABLE I. Participant information.

\begin{tabular}{lcc}
\hline \hline & Age of diagnosis & Style of course \\
\hline Participant 1 & 20 & Lecture \\
Participant 2 & 16 & SCALE-UP \\
Participant 3 & 22 & SCALE-UP \\
Participant 4 & 14 & Lecture \\
Participant 5 & 11 & SCALE-UP \\
\hline \hline
\end{tabular}

participants' diagnoses interacted with their course, and follow-up questions were also not intentionally focused on having participants identify diagnosis characteristics. The graduate student researcher (W. J.) conducted the interviews. Audio recordings of the interviews were transcribed verbatim for analysis.

We recruited a total of nineteen students from introductory physics and chemistry courses across three semesters. Eleven of these students identified with a diagnosis of ADHD. We chose to focus on these eleven participants to both reduce our sample (in line with recommendations for sample size for IPA) and to investigate whether individuals with a similar disability diagnosis reported similar experiences in postsecondary STEM courses. To further focus and reduce our sample, the lead author did a preliminary search through the eleven participants' transcripts, going line by line and identifying instances where participants made explicit connections between their diagnosis and how it affected their interaction with their postsecondary courses. Because of our social relational perspective of disability, these statements were necessary to identify a participant's diagnosis characteristics, which in turn were necessary to identify disabling barriers. W. J. selected five participants for analysis based on the numerous, explicit statements made during both of their interviews (beginning and end of semester) about how their diagnosis affected their interactions with day-to-day life. Though participants were recruited from both introductory physics and chemistry courses, these five participants were coincidently only in introductory physics courses.

Table I displays the participants' pseudonym, the age at which they were diagnosed with ADHD, and style of course they were enrolled in. ${ }^{3}$ At this university, introductory physics students have a choice between two styles of courses: traditional lecture or SCALE-UP. SCALE-UP courses combine typical lecture, recitation, and laboratory course components, and instructors are encouraged to reduce lecture time to allow time for students to engage with content through worksheets, labs, practice problems, and other student-centered activities [59]. To support inclass group work, the SCALE-UP course uses a unique classroom environment (e.g., large round tables). Research

\footnotetext{
${ }^{3}$ We did not collect additional demographic data such as race, gender, or LGBTQ identity as we did not frame our study using an intersectionality lens.
} 
has shown that SCALE-UP increases course-level learning outcomes and particularly supports course outcomes for underrepresented populations, such as women and Black, Indigenous, and People of Color students [59]. However, we are not aware of any work that investigates the experiences of students with disabilities in SCALE-UP courses. While students have a choice between traditional and SCALE-UP physics courses at this university, many students who have not previously taken a SCALE-UP course are not aware of these differences when enrolling, even though short course descriptions are provided in the online course registration portal.

\section{Process for analysis}

Following the IPA process described by Smith and Osborn [53], we started with each researcher independently reading and rereading the transcripts. Next, we generated "comments" that summarized, made connections across, and/or provided a preliminary interpretation of instances where a participant identified a diagnosis characteristic or expressed an interaction between a diagnosis characteristic and some course structure. Once one of the researchers identified one of the instances defined above, we notified the other researchers and discussed what the participant expressed and how to annotate the idea. After commenting on an entire transcript, we then went through each comment and generated "themes", "... which aim to capture the essential quality of what was found in the text" (p. 68). To identify the superordinate themes (main points), we reviewed the themes expressed by each participant. To facilitate this process, we each independently generated a short narrative of the ideas and experiences that we identified to be the most salient across the participant's themes. We discussed these narratives to reach consensus about the superordinate themes a participant expressed. The graduate student researcher (W. J.) then organized the themes under these superordinate themes, with each theme only being represented in one superordinate theme. The superordinate themes, and the themes organized underneath them, were presented to the other researchers (K. L., C. B.) for their feedback and revisions. We discussed this organization and reached a final agreement on which themes should be represented under each superordinate theme.

We worked through these analysis steps independently and iteratively for each participant. Because each participant could uniquely identify diagnosis characteristics, we aimed to not have the findings from one participant influence our analysis of another's interview transcript at this stage.

Finally, we met to generate an overall table of superordinate themes based on the superordinate themes from every participant. IPA focuses on describing similar experiences from multiple participant's perspectives. In alignment with this goal, we identified subthemes based on ideas that two or more participants expressed. Further organization was necessary due to the number of subthemes generated, so we generated superordinate themes which grouped the subthemes and allowed us to present a cohesive narrative for our findings.

In the previous meetings, we did not document which specific participants expressed each subtheme. To address this lapse in record keeping, each researcher independently went through each subtheme and identified which participants expressed the subtheme. We then met again to reach consensus on which participants expressed each subtheme. Each participant was represented in at least one of these superordinate themes. The graduate student (W. J.) then organized this list of superordinate themes into a narrative account and connected findings to previous literature [53]. All three researchers gave their input about this narrative, and the final result is presented in this paper. It is important to note that at every step of analysis, we checked any claims or interpretations against the transcripts "to make sure the connections work for the primary source material-the actual words of the participant" [53] (p. 72).

\section{E. Power dynamics}

To address the power dynamics ${ }^{4}$ between the graduate student (W. J.) and undergraduate students (K. L, C. B.), we established norms that every researcher's perspective was equally valuable. To support the established norms, researchers were encouraged to present their interpretations and disagree if they had differing opinions. If a disagreement occurred during analysis, we discussed the topic until an agreement was reached among all researchers. Though many disagreements occurred, every discussion of these disagreements resulted in all researchers agreeing on one interpretation. The intent of these practices was to support each researcher's interpretations being equally valued, but we acknowledge that the imbalance of power between researchers can result in this goal never fully being achieved [60]. The consequence is that the graduate student's interpretations may have been more accepted, despite intentional efforts to prevent any researcher's interpretations being dominant.

\section{F. Building the trustworthiness of our interpretations}

The lead researcher (W. J.) trained the other two researchers (K. L. and C. B.) in the IPA process. In these independent training sessions, the lead researcher went through an example transcript with the other researcher to practice identifying instances where a participant made explicit connections between their diagnosis, impairment,

\footnotetext{
${ }^{4}$ We recognize that variation among aspects of our identities, such as gender, race, ethnicity, disability status, age, and position within the university, resulted in imbalances in power and authority.
} 
TABLE II. Superordinate and subthemes and their representation across participants, organized by research question.

\begin{tabular}{|c|c|c|c|c|c|c|}
\hline \multirow[b]{2}{*}{ Superordinate themes } & \multirow[b]{2}{*}{ Subthemes } & \multicolumn{5}{|c|}{ Participant } \\
\hline & & 1 & 2 & 3 & 4 & 5 \\
\hline \multicolumn{7}{|c|}{$\begin{array}{l}\text { RQ1: What diagnosis characteristics do students with ADHD associate with their diagnosis, and how do students view these } \\
\text { diagnosis characteristics? }\end{array}$} \\
\hline \multirow{2}{*}{$\begin{array}{l}\text { 1. Diagnosis characteristics could be } \\
\text { challenging or beneficial }\end{array}$} & Beneficial diagnosis characteristics & & $\mathrm{X}$ & & & $\mathrm{X}$ \\
\hline & Challenging diagnosis characteristics & $\mathrm{X}$ & $\mathrm{X}$ & $\mathrm{X}$ & $\mathrm{X}$ & $\mathrm{X}$ \\
\hline \multirow{2}{*}{$\begin{array}{l}\text { 2. ADHD is understood socially and } \\
\text { understanding their diagnosis supports } \\
\text { student agency }\end{array}$} & Understood in relation to others & $\mathrm{X}$ & $\mathrm{X}$ & $\mathrm{X}$ & $\mathrm{X}$ & \multirow[t]{2}{*}{$\mathrm{X}$} \\
\hline & $\begin{array}{l}\text { Agency supported by understanding } \\
\text { of diagnosis }\end{array}$ & $\mathrm{X}$ & $\mathrm{X}$ & $\mathrm{X}$ & $\mathrm{X}$ & \\
\hline \multicolumn{7}{|c|}{$\begin{array}{l}\text { RQ2: What course structures interact with students' diagnosis characteristics to support or disable students with ADHD in physic } \\
\text { and nonphysics courses? }\end{array}$} \\
\hline \multirow{3}{*}{$\begin{array}{l}\text { 3. Course structures lead to disabling } \\
\text { and supportive experiences }\end{array}$} & Personal practices affected by course structures & $\mathrm{X}$ & $X$ & \multirow[t]{3}{*}{$\mathrm{X}$} & $\mathrm{X}$ & \multirow[t]{3}{*}{$\mathrm{X}$} \\
\hline & Insufficient time on tests introduced barriers & $\mathrm{X}$ & $\mathrm{X}$ & & $\mathrm{X}$ & \\
\hline & Extra test time as "unfair" advantage & $\mathrm{X}$ & $\mathrm{X}$ & & $\mathrm{X}$ & \\
\hline \multirow[t]{3}{*}{$\begin{array}{l}\text { 4. Disabling course structures have } \\
\text { a greater effect in physics courses }\end{array}$} & $\begin{array}{l}\text { More time needed for learning and expressing } \\
\text { understanding }\end{array}$ & $\mathrm{X}$ & $\mathrm{X}$ & $\mathrm{X}$ & & \\
\hline & Barriers to staying on pace & $\mathrm{X}$ & & $\mathrm{X}$ & & \\
\hline & SCALE-UP course supports and barriers & & $\mathrm{X}$ & $\mathrm{X}$ & & $\mathrm{X}$ \\
\hline
\end{tabular}

and their experiences in college courses and generating comments and themes.

As described in the positionality section, the research team represents a range of disability identities, which increased our ability to generate trustworthy interpretations. While there are numerous studies that have identified impairments commonly associated with ADHD [61,62], we followed recommendations found in IPA literature to bracket (i.e., put aside) our prior perspectives and experiences regarding disability during analysis [53]. We only generated comments and themes based on what the participant expressed regarding their diagnosis characteristics and which of their diagnosis characteristics interacted with course structures. Additionally, researchers were encouraged to question each other's generated interpretations and inquire how a participant's statement expressed that idea. Since researchers had varied perspectives, differing interpretations could arise and researchers would have to defend their interpretations based on what participants expressed. This process supported interpretations being more aligned with the participant's own descriptions of their experiences and is a form of ongoing peer review, which Creswell and Poth identify as helpful in building trustworthy interpretations [63]. While IPA allows for making connections to previous literature throughout analysis, we chose to make these connections after first presenting participant's perspectives. This decision was made to emphasize the uniqueness of each participant's experience of disability [11].

\section{FINDINGS AND DISCUSSION}

We identified four superordinate themes across participants: (i) diagnosis characteristics could be challenging or beneficial, (ii) ADHD is understood socially and understanding their diagnosis supports student agency, (iii) course practices lead to disabling and supportive experiences, and (iv) disabling course structures have a greater effect in physics courses. Table II shows these superordinate themes organized under the relevant research questions, along with their subthemes and the participants who expressed them.

Superordinate themes 1 through 3 refer to participants' general postsecondary experiences; the experiences reported here may have also occurred in the participants' physics courses, but they did not exclusively occur in physics courses. Superordinate theme 4 reports experiences participants attributed exclusively to physics courses.

Though we identify diagnosis characteristics and participant perspectives of them, we do not provide recommendations for how these diagnosis characteristics can be reduced or eliminated. Such an approach would be aligned with the medical model. Rather we report the diagnosis characteristics and how participants understand them because we identified the course structures that interacted with diagnosis characteristics to result in supportive or disabling experiences. We report how participants view their diagnosis characteristics to reveal the negative impact of our ableist culture, especially because disability stigma became a disabling barrier that prevented students from using accommodations. Figure 1 shows how all the superordinate themes tie together to describe participants' supportive and disabling experiences in physics courses.

Findings will be presented by first expressing our interpretations of participant's perspectives within each superordinate theme. We found that many participant perspectives were aligned with a medical model view, likely due to the pervasiveness of this perspective in our 
RQ1: Participants' understanding of having ADHD

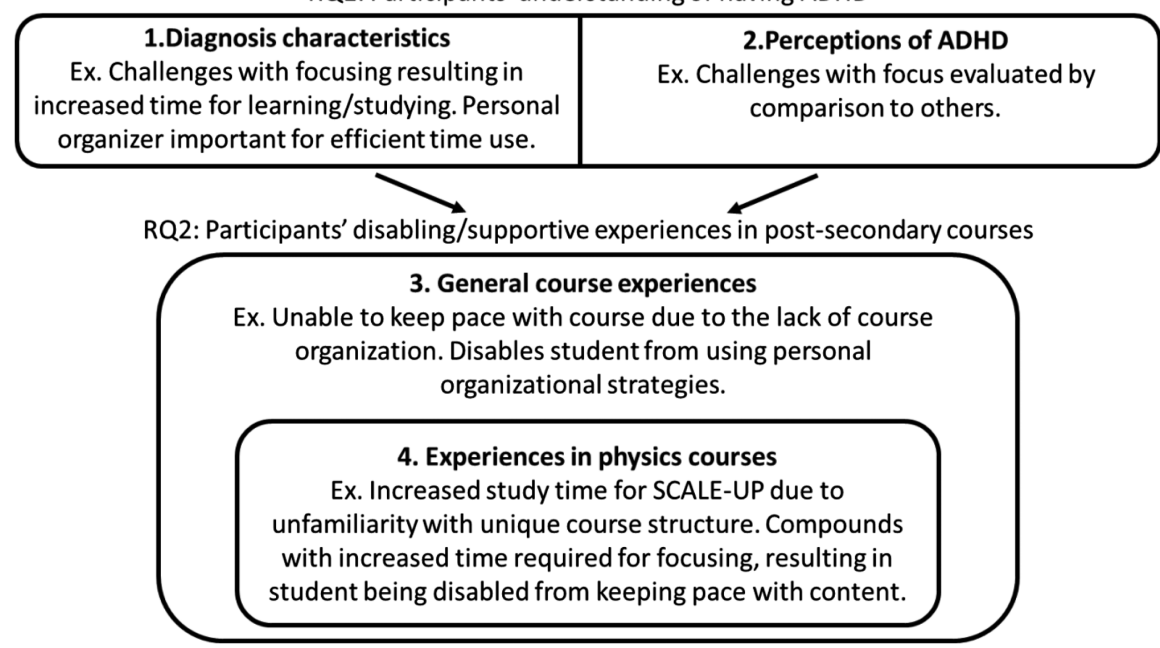

FIG. 1. Diagram showing how superordinate themes 1 and 2 give a description of participants' understanding of having ADHD, and how understanding ADHD influenced superordinate themes 3 and 4, which describe participants' experiences in postsecondary courses. This demonstrates how superordinate theme 4 includes barriers that existed throughout students' postsecondary experience and were increased in their physics courses. Examples from findings are included in each section to clarify connections between superordinate themes.

society and academic institutions, which are markedly ableist [64]. We seek to report participant's interpretations of their experiences, but we also use our knowledge as researchers to contextualize these findings using a social relational perspective lens. The result is that our interpretations are structured to identify how course structures interact with diagnosis characteristics to result in disabling or supportive experiences.

We follow participants' perspectives with how the perspectives relate to previous research and/or recommendations for how instructors can reduce identified course barriers. In alignment with the social relational perspective, all recommendations are targeted at how course structures or instructor perceptions can be modified. This contrasts with a medical model view which would recommend practices for changing students and/or their behavior.

\section{A. Challenging and beneficial diagnosis characteristics}

Since supportive or disabling course practices are characterized by interactions with participants' diagnosis characteristics, we first must investigate participants' diagnosis characteristics. Participants identified diagnosis characteristics of ADHD that included difficulties with focus, being prone to distractions, difficulties with keeping mental track of tasks and structures, and frequently ruminating about abstract concepts taught in their courses. These diagnosis characteristics were reported as beneficial or challenging based on their impact on day to day life.

\section{Beneficial diagnosis characteristics}

Participant 2 and participant 5 identified positive effects their ADHD had on their learning, but only participant 5 gave specific examples of what the positive effects were. When participant 5 was asked if having ADHD has shaped their experience in their physics course, they expressed that a diagnosis characteristic of having ADHD for them was thinking more often, especially about abstract concepts which were taught in their courses and how they were connected. Participant 5 shared how this diagnosis characteristic benefited their learning in physics courses: " $U m$, in, in some manners I think about it [physics] a lot more, I think, than a lot of other people do. Just because that's, there's a lot more thoughts always coming in. I feel like one thing I can do a lot better than maybe other students can is just very well abstract things. Um, like see that, 'Oh, yeah. I think I used this over here, and so it could be relatable over here' because, you know, followed a similar pattern..." Thus, participant 5 viewed their rumination about abstracts concepts, an ADHD diagnosis characteristic, as positively affecting their learning in physics.

Connections to literature.-The affirmative model of disability embraces the idea that diagnosis characteristics can be beneficial, challenging the traditional view of normality by asserting that an individual's diagnosis characteristics can result in a positive identity [16].

\section{Challenging diagnosis characteristics}

All five participants identified challenges arising from diagnosis characteristics which they explicitly connected to having ADHD. These diagnosis characteristics included difficulties with focus, being prone to distractions, and difficulties with keeping mental track of tasks and structures (e.g., how a course is designed, reoccurring 
commitments, interactions between school and social life). Participant 3 shared that difficulties with focus were associated with having ADHD and that maintaining focus was a time intensive and exhausting task. Specifically, Participant 3 stated: “...it takes me a long time to focus. So... since it [focusing on task] takes me so long and since my focus time is so low... it takes a long time to get focused. It doesn't last that long. So... after that energy expends, then it's like, okay, get focused again."

Participant 2 identified being easily distracted as a characteristic of their ADHD diagnosis and that this affected their learning during lecture because they were likely to get distracted: "Yes, 'cause I have ADHD, so it's really easy for me to get distracted, so when someone's lecturing I just kind of, the moment I like lose focus for a little bit and I come back and I don't know what's going on."

Participant 1 expressed that they had only recently been diagnosed with ADHD, and they were beginning to understand themselves better by investigating the diagnosis of ADHD. When asked if they had encountered any challenges due to their diagnosis, participant 1 identified a challenge with remembering the tasks required of them from school and their social life and described that they have addressed this challenge by having their schedule in a digital format: "...actually the biggest barrier for me was understanding exactly how it is I should structure my life [shows Google calendar on phone to interviewer]. If, this was something that I, if I hadn't started doing, my life would, I don't know where it'd be."

Connections to literature.-Challenges with focus, attention, and keeping track of tasks are markers that clinical psychologists use when diagnosing individuals with ADHD [65]. We see that participants do not characterize their diagnosis characteristics as markers given by external, third parties, such as clinical psychologists. Rather we see that the participants self-identify with these diagnosis characteristics and that they use this understanding of their diagnosis to understand themselves and how they interact with the learning environment. The challenges described here are attributed to personal qualities (i.e., diagnosis characteristics) which are independent of social structures. This finding aligns with the social relational perspective's argument that diagnosis characteristics have qualities that cannot be remedied by social change. However, in later sections we report how course structures interact with these diagnosis characteristics to result in disabling barriers.

Our findings also reveal that participants identified more negative impacts on their learning than positive impacts. This imbalance can result in a view of ADHD as being inherently negative. Previous studies in which students with ADHD were interviewed or surveyed have also found students identified more negative diagnosis characteristics than positive diagnosis characteristics. Negative self-views of ADHD can cause students to have lower self-esteem and a lower perceived ability to succeed in college $[35,66]$. The medical model offers an interpretation that anxiety and depression are often comorbid with ADHD; however, the social model pushes us to ask, "to what extent are comorbid anxiety and depression mediated by experiences of institutional and interpersonal ableism?" [67] (p. 3). Negative feedback about ADHD diagnosis characteristics may "have a detrimental impact on an individual's self-concept and psychosocial functioning" [67] (p. 3). Thus, negative self-views may be an example of internalized ableism.

Recommendations for instructors. - If instructors hold the viewpoint that ADHD is inherently negative, a consequence could be lower expectations of students with disabilities or doubting their ability to succeed [68-70]. This could lead to instructors not engaging with students with disabilities or being less willing to enact practices to support students with disabilities. Therefore, we recommend that instructors recognize and celebrate the variability in learners' needs, interests, and abilities. By doing so, instructors support a culture which celebrates diversity, rather than marginalizing differences. For example, instructors could highlight strengths related to diagnosis characteristics that are relevant for the discipline. Research has found that postsecondary faculty recognize strengths such as "ability to focus for extended periods, adherence to rules and protocols, and outside-the-box thinking" among college students who have autism [71]. Other examples include hosting speakers with marginalized identities [71] or otherwise engaging students in learning about the backgrounds of physicists.

For example, Dounas-Frazer designed an activity through which he features women and gender minority physicists-mostly women of color-in the physics courses he teaches [72]. Developed in 2019 in consultation with Byrd who was then in an accountability partnership with Dounas-Frazer [73], the activity comprises four major components: (i) about three times per week, during lecture, the instructor features a physicist by giving a three- to fiveminute presentation about the physicist, their research, and their educational and career pathway; (ii) after class, the instructor uses an online course management program to provide students with links to interviews, blogs, podcasts, or videos that they can use to learn more about the physicist featured during lecture; (iii) on the take-home portion of each midterm exam, the instructor includes a credit-bearing question that prompts students to identify a featured physicist who interests them, explain what they find interesting about the physicist, and describe whether and why they view the physicist as a role model; and (iv) on the last day of class, the instructor shows a collage of all the physicists who were featured in class and discusses the importance of identifying multiple, diverse role models. 
The activity that Dounas-Frazer designed can be adapted in straightforward ways to focus more explicitly on physicists with disabilities. Indeed, Dounas-Frazer has featured K. Renee Horton [74] and Wanda Díaz Merced [75] as part of this activity, each time describing how their disabilities constrained and informed their educational and career pathways.

\section{B. ADHD is understood socially and understanding the diagnosis supports student agency}

Participants primarily expressed diagnosis characteristics in comparison to others, specifically in the context that tasks were more challenging for participants than their peers, resulting in negative self-views and possible internalized ableism for some participants. Some participants found that by understanding their diagnosis, they were able to identify strategies that increased their likelihood for success.

\section{Understood in relation to others}

Participants expressed varied perspectives about their diagnosis characteristics; this is not surprising since participants' perspectives are shaped over time and influenced by factors including when they were diagnosed, the supports they have received, and their interactions with others [76,77]. A subtheme identified in all participants' interviews was that diagnosis characteristics were almost always referenced in comparison to others, and "others" were typically participants' peers in their courses. For example, participant 1 expressed the consistent feeling that it takes them more effort to accomplish the same tasks as their peers: "I tell myself that everyone here has the efficiency of a God, whereas I have to do more work for the same or less results. And that's just something that I've always had to deal with..."

When participant 4 was asked if they had encountered any barriers to learning due to having ADHD, they responded with comparisons to their peers. Specifically, they identified that a diagnosis characteristic of having ADHD was that they required more time to process and would make more mistakes than their peers. They also identified that these diagnosis characteristics made them have lower self-worth in the past: "...for me feeling like I'm less than anyone else, like, I used to feel like that, I guess, just because, like, I think it's a little bit of more time for me to process things and, like, I tend to make a little bit more mistakes than what other people do..."

These findings show us that diagnosis characteristics were primarily characterized by the participant's ability in some area, and participants frequently used their perceptions of peers' abilities as a benchmark for their own. This finding is in line with the social relational perspective, which proposes that diagnosis characteristics are socially understood [9].
Connections to literature.-The majority of participants' comparisons to others were framed such that the participant felt less capable compared to their peers. Previous studies have also reported the negative consequences of such comparisons on students' motivation and self-efficacy $[35,66,78]$. Additionally, Baines' study of high school science students with disabilities found "when a student with a disability is negatively perceived by those around him, he can be restricted in his access to valued opportunities that might be related to abilities he would like to develop in relation to personal goals" [79] (p. 36).

Recommendations for instructors. - In an earlier paper, we presented an experience with an introductory physics instructor's bias from a student who identified with an executive function disorder. The student shared with the instructor that the student would be using the extra test time accommodation, and the instructor responded in surprise since they perceived the student to be strong in the content and did not expect the student to have a disability [80]. In an interview, the student explained: "He [the instructor] thinks that 'Oh, because she's strong in the subject, she wouldn't have a disability. She doesn't need accommodations.' So the fact that he found out, he was like 'I'm so shocked, like.' I guess he was being like biased or stereotypical." We interpret the instructor's response as an example of ableism, "a set of beliefs, processes and practices that produce - based on abilities one exhibits or values - a particular understanding of oneself, one's body and one's relationship with others of humanity, other species and the environment, and includes how one is judged by others" [Wolbring [81] (p. 1)].

Ableist mindsets dominate our society and academic institutions, leading to the marginalization of individuals with disabilities through courses which are not designed to support individuals with disabilities and instructors who doubt the capabilities of students with disabilities [82]. Every student deserves instructors who believe they can succeed. Because our society is shaped by ableism, each of us is capable of ableist assumptions. Instructors can support students with disabilities by reflecting on their ableist beliefs and moving towards a perspective that all students can succeed. By shifting from a mindset of ableism to a mindset where all students are perceived to be capable, we move towards an inclusive and supportive classroom environment where all students feel valued and supported [83]. However, we must be aware that our culturally held beliefs about what it means to be "capable" are impacted by ableism; for example, the pedagogical trend toward multimodality could support variation in learners' needs, abilities, and interests, but "has more often... demanded that students learn to max out all literacies" [64] (p. 114). Thus, what it means to be capable in physics should be operationalized in collaboration with physicists with disabilities and chronic illness. In (Un)Learning 
Disability: Recognizing and Changing Restrictive Views of Student Ability, Baines writes, "James, who deeply despised being labeled with Attention Deficit Hyperactivity Disorder (ADHD), often said he failed to see the point of science class, because he was never going to be a "good science student." Instead, he saw himself as a "scientist," an identity that he did not think could exist within the confines of academic expectations" [79] (p. 67). We need to ask students like James about the differences they recognize between being a "good science student" and being a scientist to improve our disciplinary understanding of what it means to be capable.

\section{Agency increased by understanding diagnosis characteristics}

Participants 1, 2, 3, and 4 shared how understanding their diagnosis characteristics has empowered them to make informed decisions about how they chose to view their diagnosis, allowing them to push back against internalized disability stigma, and to recognize the course structures that support their success.

Participants 1, 2, 3, and 4 all identified that they once held negative viewpoints towards their diagnosis and its diagnosis characteristics; however, they began to generate more positive views of their diagnosis when they began to view their diagnosis as a way to understand how they think and behave. A critical part of this process was a recognition that challenges do not have to be viewed as challenges, and that there are positive diagnosis characteristics associated with having ADHD. Participant 1 encapsulates these ideas saying: "Yup, but, but it's [perspective about disability] changing 'cause, um, I've realized that, you know, this weakness has become my strength...it's kind of perspective that it's something I have to work on 'cause it's something that, you know, [indiscernable], um, realizing that a weakness doesn't have to be a weakness forever."

Regarding the recognition of supports needed for success, participant 1 shared that they had investigated the medical diagnosis of ADHD soon after being diagnosed. They stated how this investigation had helped them to understand that order and structure are valuable to them because organization was a cognitive challenge: "And, $u h$, attention deficit disorder is an executive function disorder, so I'm understanding why I love order and structure so much is because I don't have it and within my cognitive processes. So, when I have it in an exterior fashion it's like, it's like this is how I wish my brain would be. But it's not, so I have it on paper." We recognize that this quote seems to be aligned with a medical model of disability (i.e., disability being situated in the individual); however, instructors play a critical role in providing students the information and tools necessary for student organization, a consequence that aligns with the social relational perspective of disability. For example, a student can be inhibited from structuring their studying if an instructor does not provide access to course content or does not provide timelines for when content knowledge will be assessed.

Recommendations for instructors.-By understanding their diagnosis, participants encountered a double-edged sword that benefited them through an increased understanding of themselves but could also harm them due to negative comparisons to others. We recommend instructors provide a variety of strategies for engaging with course content so that students can engage with and practice using different methods, a process which can help students identify what is most effective for them. For example, instructors can provide multiple ways for students to review the same content outside of class (e.g., book, Power Point slides, links to instructional videos). To reduce the negative comparisons to others, we recommend instructors value and celebrate the differences that their students bring, for example, by making statements acknowledging that there is variation among learners and normalizing challenges with learning physics content. Error management training is an instructional strategy specifically focused on normalizing the process of making mistakes, and many studies have found that this perspective leads to increased learning due to its support of emotional control and metacognition [84,85].

\section{Course structures lead to disabling and supportive experiences}

Participants stated that they encountered challenges related to organization and time to complete tests. To address these challenges, participants implemented strategies such as using a planner and developing study strategies that allow for distractions. Using the social relational perspective, we focus on how courses could support or disable students from using their personal strategies based on the level of course organization. While students discuss their use of personal strategies, we do not focus on the development of personal strategies in response to diagnosis characteristics, as this is aligned with a medical model approach.

Participants also expressed that the time given on tests was insufficient for them to express their understanding. The barrier of insufficient time on tests could be alleviated by using extra test time accommodations, however participants reported that extra test time had negative stigmas associated with it. A medical model approach would encourage students to develop better test taking strategies, however by using a social relational perspective we identify the time provided during tests as the barrier. We also identify disability stigma as a social structure which introduces disabling barriers to making use of testing accommodations.

While participants discussed their choices regarding medication, discussing medication use does not align with the our social relational-informed focus on social 
structures. We urge instructors not to discuss the topic of medication use with their students (particularly without student initiation), including "jokes" about medication use, as this is a personal topic outside of instructor's purview.

\section{Personal practices affected by course structures}

To address challenging diagnosis characteristics, all five participants implemented individual efforts which included using a planner for organization and developing study strategies that incorporated breaks. Participants reported how they could be disabled from effectively using these practices due to course structures.

The frequency and importance with which participants discussed organization strategies, such as using a planner, suggest that organization strategies were an important personal practice which participants employed. Organization was mentioned by four out of the five participants, with participants $1,2,3$, and 4 expressing planners as being key to their success. For example, participant 2 shared how they use a planner to organize every aspect of their life: "I write everything I have to do, including social engagements like when I'm going to see my boyfriend, when we have plans, when I have plans with my friends, everything. If I lose it, I wouldn't remember anything". Participant 4 shared that being organized was critical specifically because they have ADHD, and that when instructors did not provide PowerPoints before class it could inhibit the participants' use of their own organizational skills: "I don't like the teachers that they don't have, like, a game plan, right? So, they'll just, like... not put the PowerPoint up, like, until the day after...I get mad when teachers aren't organized just because, like, I know how hard it is, like, as a student with ADHD, like, I have to stay organized and if teacher isn't organized, it makes my job, like, 20, 30 times harder."

For the participants to make use of their planning strategies, they needed to know deadlines for assignments, assessments, and mastery of specific learning objectives. Participant 1 shared that it is critical for their success that their instructor provide a course schedule: "A tentative schedule is something I particularly rely on because, again, I need to plan and if I don't have that, that's not going to work." When this information was provided, the participants were able to structure their time for studying and completing assignments. When this information was not provided, participants encountered difficulties in planning their time outside of class, which participants shared could result in poor test preparation or even having to withdraw from courses. Diagnosis characteristics lead participants to value organization, but course structures influenced whether students were supported or disabled from using organizational strategies.

Participant 2 shared that taking frequent study breaks was a personal practice that supported their study time related to their diagnosis of being easily distracted. However, allowing time for breaks required that the participant had a large block of time set for studying: “... I need large blocks of time to get really small parts done because I need to do a little bit and then do something to relax and allow myself to get distracted and then come back, do a little bit.." While this strategy was helpful outside of class, participant 2 reported that long lectures without breaks disabled them from using this strategy during class. In response to this, participant 2 implemented their own breaks during class by leaving the class for a set period of time, "...generally I like go to the bathroom to just chill... I did that in high school, I've never been good at lectures, so I just go to the bathroom and hang out..."

Connections to literature.-Every strategy mentioned by participants was self-developed and this development process took time, knowledge of their diagnosis characteristics, experience, and practice. Perry and Franklin similarly found that students with ADHD developed strategies based on their understanding of their ADHD and diagnosis characteristics [35]. When participants understood the effects that ADHD had on their lives, they were better able to identify or develop strategies to engage with their courses. Organization was one of the predominant strategies reported, and previous research where students with ADHD were interviewed has also found that organization is a critical skill for students' success $[25,26]$.

By using a social relational lens, we see that the implementation of these strategies often hinged on whether a course provided certain supports. For example, a student cannot plan their studying if they do not have access to course content or do not know when they will be assessed on the content. When courses are not designed to support students' knowledge about and use of appropriate study skills, students are forced to spend time finding the best ways to study. These challenges are compounded for students with disabilities whose diagnosis characteristics require more time to complete tasks. The result of this interaction is that participants were disabled from effectively engaging with some of their courses.

Recommendations for instructors.-To support students in making use of organizational strategies, instructors should provide schedules outlining when assessments and assignments are due. To facilitate students achieving these goals, course content should be available digitally in one location so that students can easily access it. The sooner deadlines and course content are available, the better equipped students are to plan their learning outside of class.

To support students staying attentive in class, we recommend instructors provide opportunities for students to be momentarily disengaged from content without suffering from missing content. This can include providing breaks and/or providing activities where students have flexibility in the means and timing for completing tasks. 
In our later section on SCALE-UP courses, we provide a quote from participant 2 which describes how collaborative problem solving is an example of such a flexible activity.

\section{Insufficient time on tests introduced barriers}

Participants expressed varying barriers regarding time for tests, with participants 3 and 5 not encountering significant barriers and participants 1,2, and 4 seeing time for tests as a significant barrier. Participants 3 and 5 stated that they were able to maintain focus during tests, so their diagnosis characteristics did not interact with tests. When asked if using testing accommodations would affect participant 5's test performance, they said 'Um, I don't think so 'cause I don't think I really felt, uh, very distracted in the test."

On the other hand, Participants 1, 2, and 4 encountered barriers regarding time on tests, and they reported that the barriers were due to not having sufficient test time. Having sufficient test time was important due to diagnosis characteristics such as being distracted during the test time and the fact that they had a longer processing time than their peers. Participants articulated that the accommodations of extra test time and reduced distraction environment provided through the university's disability services office alleviated these barriers. Participant 4 expressed that extra test time significantly reduced the stress they experienced from being concerned about the amount of time they had to complete tests: "Oh, it [extra test time] helps so much. 'Cause, like, you're not even worried about the time at that point. You're just, like, doing problems. You're taking your time and solving them. You know. You're not, like, stressing, like, 'Oh my god, how much time do I have left?"'.

Though testing accommodations were reported as beneficial by some participants, they also introduced new barriers since the testing accommodations occurred in a separate environment. When using the extra test time accommodation, participants would miss announcements or corrections made by the instructor during the test and were often unable to ask the instructor questions during the test. Participants also expressed concern that other students could potentially notice their absence during tests, which could prompt questions of their whereabouts. Participant 4 shared how these questions outed them as using accommodations: "The only time people figure it out is, like, when they're like, um, 'save me a seat for the test', and I have to be like, 'Oh, I'm not taking the test with you guys'...And that's the only way they figure out." In the next subtheme, we present how this potential "outing" resulted in negative perceptions from peers regarding participants' accommodation use.

To receive accommodations, participants typically had to provide evidence for their diagnosis to the disability services office at the university. For one participant, this resulted in them not being able to receive accommodations due to the cost of being diagnosed. Fortunately, this individual stated that accommodations were not necessary for their success, but for a student who does need extra test time the cost of receiving a diagnosis could have been a disabling barrier.

Connections to literature.-Our findings align with previous studies where students with disabilities have reported the benefits of testing accommodations [25-27], but we also find that not all students with ADHD consider them critical for their success and the requirement and cost of diagnosis can be a barrier to accessing necessary accommodations.

Recommendations for instructors.-Since one of the course barriers is insufficient in-class time for assessments, we recommend instructors reflect on whether their learning objectives require that students express understanding within a constrained time. If not, then we encourage instructors to design assessments so that ample time is provided for all students. Options include having all students complete assessments in separate testing centers that allow more time than provided in a class period or offering alternative forms of assessment (e.g., projects), which are done outside of class.

To support students who are using extra test time accommodations, instructors can make plans with the student or disability service office about how the student can contact the instructor during the test time (e.g., providing the disability service office a phone number versus relying on email). Instructors can reduce the chance that peers will notice the absence of students using accommodations by having students sit in randomly assigned seats during exams. This supports students in keeping their confidentiality regarding accommodation use.

\section{Extra test time perceived as an "unfair" advantage}

Negative perceptions held by participants and their peers regarding extra test time were specific to the idea that extra test time gave students an unfair advantage. This negative perception is a social structure which had the consequence of disabling students from wanting to make use of services they found beneficial. Three participants (participants 1,2, and 4) were using extra test time accommodations during their physics courses. Participants 2 and 4 reported that, in the past, they felt that accommodations were unfair and subsequently did not use them in previous courses. Specifically, they felt guilty about having an unfair advantage over their peers and/or that they wanted to prove that they could succeed without the accommodations. For example, participant 2 shared how they tried not using extra test time, stating: "so in this past semester I felt, I felt really bad about using [extra test time accommodations] because then it was just, I do have ADHD, I'm kind of like, 
I do have ADHD but it's not fair like I don't like looking at my peers and being like I'm doing better because I have whatever. So I stopped using it and for physics, for Physics 1 my first test I did really badly and it was because I like knew the information, but the way I learn I had to like go through step by step, this is how this goes, this is how this goes and we didn't have enough time for that..." Participant 1 also experienced guilt and negative selfperceptions from using extra test time. Though participant 1 reported continuing to use testing accommodations because of the significant benefits they experienced, they did not make any explicit statements that those negative perspectives have changed. Here participant 1 shares their mindset regarding their past and present negative feelings experienced due to using accommodations: “... [sigh] it [requesting accommodations] made me feel weak...it's still a little uncomfortable because I mean I, for example, I don't I don't tell my friends about it." Accommodations are implemented to reduce discriminating barriers, and participants have reported that they are effective in doing so. However, it is concerning that these supports can result in participants experiencing such negative self-perceptions as students are going to be unlikely to use a resource that results in them feeling less than others. This supports the hypothesis that students may receive "misattuned and negative feedback from the relational environment" that impacts their self-concept [67] (p. 40).

Participants 1 and 4 also expressed that some peers seem to hold the perspective that the extra test time accommodation is an "unfair" advantage. Participant 4 discussed that interactions with friends who said they were jealous of the participant's use of the extra test time accommodation led the participant to not make use of the extra time: "I used toI used to feel bad about it almost like, I used to feel, like, kinda guilty, 'cause, like, everyone else was, like, getting half the time I was taking when I had tests, so, like, in the beginning, I actually just went to class and just took my tests, like, with the rest of the class, just because, like, some of my friends were, I mean, I wouldn't say making fun of me for it but they were just, like, kind of jealous of me..." Participant 1 reported that they had not heard anyone explicitly share negative views towards extra test time, but the participant still knew these negative views of accommodations existed, stating: “... I haven't necessarily been exposed to it, but I know there's a stigma around it [extra test time], and it's still something I guess I just have to deal with for now."

Connections to literature.-Previous studies reported students with disabilities experience views from their peers that extra test time provides an unfair advantage [26,35]. In our study, we found that others' negative views can interact with participants' own views towards the fairness of accommodations, possibly leading students to not use this accommodation that may be critical for success. Whether extra test time results in increased performance for students with disabilities is contested at the postsecondary level as some studies have found increased performance on tests when extra test time is provided to students with various diagnoses [86-88], whereas other studies have found no increase in performance $[86,89]$. However, none of these studies are specific to STEM, an important distinction in light of the increased processing time students need in STEM content areas [90]. A literature review on STEM accommodations by Ofiesh found little research investigating the effectiveness of accommodations in STEM, but the research which has been done has shown extra test time benefits students diagnosed with learning disabilities [90].

Recommendations for instructors. - We view extra test time as a fair and necessary accommodation. The participants in this study expressed benefits from extra test time accommodations beyond improved performance on their exams, such as significant reduction in anxiety. We recommend that instructors encourage and support students with disabilities in using extra test time accommodations.

\section{Disabling course structures have a greater effect on student learning in physics courses}

Participants 1,2, and 3 shared that they encountered barriers specific to STEM courses along with many barriers which were heightened versions of barriers experienced in other courses. Barriers specific to STEM were most often due to interactions between course features and diagnosis characteristics that increased the time required for tasks. Participants 4 and 5 also discussed supports and barriers in STEM courses, but they did not identify these barriers to be distinct from the barriers they experienced in other courses, as discussed in the preceding sections.

\section{More time needed for learning and expressing conceptual understanding}

To succeed in physics courses, participants recognized that memorization was insufficient and that they also needed to know how to apply the learned concepts. Participants 1, 2, and 3 identified that the time needed to understand physics concepts significantly added to the increased time required for tasks due to participants' diagnosis characteristics. For example, participant 2 expressed a diagnosis characteristic of being easily distracted that resulted in increased processing time. They shared how physics courses exacerbated this increased processing time due to the time required to think through a problem and that, when insufficient time was given, they had to rely on memorization: “...for Physics 1 my first test I did really badly and it was because I like knew the information, but the way I learn I had to like go through step by step, this is how this goes, this is how this goes and we didn't have enough time for that so I was like really downtrodden and then I found out basically ... I found out 
you just kind of have to do that thing three times, go over the questions three times and then you'll do well on the test, and I did that, and I was really happy I did well, but I hated it. It was all memorization."

The interaction between diagnosis characteristics and time for processing was especially evident when participants discussed physics assessments. Participants 1 and 2 expressed that the extra test time accommodation was even more critical for success in physics compared to other classes, with one of the biggest benefits being reduced stress and anxiety. For example, participant 2 identified that extra test time was especially important in their physics course since it reduced the stress they experienced from requiring time to effectively engage with the content: “... things like math and physics, they [extra test time and reduced distraction environment] can be pretty damn important just 'cause like having, knowing I have that extra time makes me, makes my anxiety go down because I'm always that type of person that I'm up there 'till like the last minutes for the thing 'cause it just takes me a while."

Connections to literature.-The time requirement for conceptual understanding being higher than for rote memorization is a well-known characteristic of physics content $[45,91,92]$, but for our participants this compounded on the increased time they already took to complete tasks compared to their peers.

Recommendations for instructors.-Instructors can support students' time management by providing class resources in an organized and consolidated format in an online location, such as the course learning management system. Since insufficient time to complete tests was found as a significant barrier, we also encourage teachers to provide ample time for all students to complete assessments, as being able to complete a test or show mastery of a topic in a set amount of time is rarely the learning objective. As testing accommodations are commonly used to address this barrier, we recommend that instructors make statements in class supporting students to use accommodations and collaborate with their institution's disability services office to provide an equivalent testing experience for all students [93].

\section{Barriers to staying on pace and determining how to study}

Participants 1 and 3 expressed that physics courses were uniquely challenging in identifying useful study strategies. For example, Participant 3 identified that the study strategies they employed in other courses were not working in their SCALE-UP physics course and that they needed to develop new methods: "So, I'm like on the second or third week before I'm like, hey, this seems like this is going to be like this... you know like I need to rework my game plan [how they study]." Participants were able to identify the textbook and lecture slides as resources to study from but reported difficulties with how to make use of these resources. As the course progressed, they began to pick up effective study strategies, such as using an iterative note taking strategy with the textbook or learning how to effectively preview the PowerPoint slides before class. However, these strategies were self-taught and often learned after they had already taken a test or two. When participant 1 was asked if they came into the class knowing how to engage with the physics textbook, they expressed that they had encountered challenges initially engaging with the textbook, but eventually developed a strategy of reading the text iteratively: "Oh man, I mean at first no. At first when I would read the chapters it was, it was hard because um some of the concepts are ... they're not intuitive, you can't really see them happen and that was the biggest challenge at first, but um I think repetition was a key for me, just reading it again."

The interaction between the time needed to develop study strategies and the additional time required to engage with the course material due to diagnosis characteristics resulted in participants falling behind the pace of the class. The consequence of this for participant 3 was that they were not able to fully prepare for the first exam and ended up performing poorly: "... and so the test was for um... chapters one through four, but I had only gotten up to chapter one. So, I did get a low grade on a test, but I knew everything of chapter one and I knew like half...on chapter two." Participant 3 expressed that instructors could support students with such barriers by spending time at the beginning of the course to give students guidance about engaging with the content: "So having a foundational week would be the most amazing thing, I think, not just for people with focus issues, but students in general just because if you're having focus issues and attention issues, most likely you probably don't have the best study skills ... but if you have a foundation week, the teacher is like ... telling you the first week, 'Hey! we're not going to jump into the material right now, but I really want you to understand how this class is set up, how you can be successful in this class'..."

Connections to literature.-Previous studies have also found that students with disabilities may need more time than their peers to complete tasks [26,94], and we find that physics courses can exacerbate this through a lack of sufficient course-level supports. Instructors can support students to use their time effectively by highlighting cognitive strategies that support learning physics content, such as metacognition [95-97] and critical thinking $[98,99]$.

Recommendations for instructors.-Though we may assume students naturally learn study skills in physics courses by engaging with course content, our findings reveal that more intentional practices need to be implemented to scaffold students in developing study skills. 
Additionally, instructors should recognize that students may be confused about how to interact with their physics textbook. Students may feel that the layout of the textbooks in other STEM courses, such as biology, follows closely along with the course content to be memorized and understood for the exams. On the other hand, in a physics course, students must understand the concepts and be able to apply this understanding to solve problems. Thus, instructors should be explicit about the extent to which reviewing the textbook is likely to prepare students to demonstrate their understanding of the content and alert students to other study strategies they should be using, such as working out new problems.

\section{SCALE-UP course supports and barriers}

Participants 2, 3, and 5 enrolled in SCALE-UP-style physics courses, and they expressed that they had never had a course like SCALE-UP before and needed to approach it differently than their other courses.

Participant 2 reported that a benefit to the SCALE-UPstyle course was that the emphasis on student engagement allowed the participant autonomy in how they learned the material, which helped with diagnosis characteristics related to difficulties with sustained focus: "But like when I'm in Studio [SCALE-UP], I can space out and come back. They're still working on the same problem or a little farther, I just kind of figure it out, and I go back and I get like, it happens a lot. Yeah, I'll just be like this is what you're getting confused about. It's really nice I don't have to worry about getting distracted." However, participant 5 reported that the unique layout of the classroom combined with students engaging with content had the potential to increase difficulties with attention:

Participant 5: ...occasionally like zoning out or being distracted in class...

Interviewer: Is there anything in class that makes it easier to get distracted?

Participant 5: ...Um, maybe potentially the way the class is arranged. We're just kind of around circular tables so like everywhere you look there might be like hands waving or things...But, um, and we have the two like, uh, boards on either side, so as long as I like focus on one of those and try to control myself, I'll be fine..."

From participant 2, we identify that the logistical structure of a SCALE-UP course supports students with ADHD by providing autonomy and allowing space for being distracted. However, participant 5 reports that the physical layout of a SCALE-UP course can result in barriers to learning due to increased distractions.

As discussed previously, participant 3 expressed barriers to staying on pace with the class due to not knowing how to effectively engage with physics content. These barriers were compounded by the unique structure of the
SCALE-UP course. Participant 3 shared how they had never been in a SCALE-UP course before and that they had to not only learn the content, but also how to learn the content in a SCALE-UP-style course: "...but I think the hardest part was like not knowing how to prepare for the class and like not knowing how to study...I've never been in a class like this [SCALE-UP class], so it was kind of different...[explanation of SCALE-UP structure]...you have to like kind of learn first and then when you go to the class like if you have questions and stuff, this is where you need to get those straightened out. Um... So I wish I would've known how to prepare for the class before..."

Connections to literature.-Significant work has been done to show that SCALE-UP courses provide increased learning when averaging across a whole class [59]. However, we find that SCALE-UP courses introduce barriers for students with ADHD, which builds evidence for the importance of considering the variability of learners in a course and not defaulting to supporting the "average" student. It is important for researchers to pay attention to variation, or lack of variation, across the learners we include in our research. For example, a recent review of physics education research found a lack of diversity in the populations of students included in research and a disproportionate amount of students included who have a higher than average math preparation [100].

Recommendations for instructors.-Though the barriers that emerge from learning in the new context of SCALEUP may be heightened for students with disabilities, SCALE-UP is likely a new way to learn for many students. Therefore, we can support all students in SCALE-UP courses by implementing practices that teach students how to effectively engage with SCALE-UP courses, such as practices students can use to prepare outside of class and how to effectively engage with content in class. An example of how instructors can support students is given by participant 3 who expressed an interest in a "preparation week" at the beginning of the course focused on developing skills for effectively engaging with both the SCALE-UP course and the physics content.

\section{SUMMARY}

In this study, we found that students with ADHD reported both challenging and beneficial diagnosis characteristics. By understanding their diagnosis, participants were able to identify what they needed to succeed, but this understanding could also lead to negative self-perceptions, possibly in the form of internalized ableism resulting from negative feedback from the relational environment. Some students shifted from negative to positive self-perceptions regarding their diagnosis characteristics by learning more about their diagnosis characteristics and implementing practices and strategies in response. Participants' 
implemented strategies could be ineffective when courses did not support their use, and time for tests was reported as a significant course barrier. Extra test time could alleviate time constraints, but this accommodation could also be viewed by participants and peers as giving an "unfair" advantage. Participants reported that they were unable to use existing study strategies in physics courses due to the requirement for conceptual understanding. Participants' physics courses did not support students in developing these skills at the beginning of the course, so participants reported barriers to staying on pace with the course. Tests in physics courses were also a challenge due to the increased time needed to critically reason through problems, and participants reported that the allotted time for tests was insufficient and therefore a barrier to expressing their understanding. SCALE-UP courses benefited students through the autonomy given but could also introduce barriers from increased distractions.

By using a social relational perspective of disability, we found how diagnosis characteristics interacted with course structures to result in participants being prevented from effectively learning and expressing understanding of course content. This contrasts with a medical model aligned analysis which would instead focus on how students need to individually improve to succeed. Physics courses presented similar, but heightened barriers compared to nonSTEM courses, specifically in the areas of developing study skills, keeping pace with the course, completing tests in the allotted time, and knowing how to prepare and engage with the SCALE-UP course style. As represented in Fig. 1, students found that understanding their diagnosis characteristics contextualized their experiences and empowered them to select and implement useful study strategies. However, the usefulness of the study strategies varied between physics and nonphysics courses and could be supported or disabled by instructor-level practices.

Instructors make a choice, either examined and intentional or unexamined and unintentional, about where they situate disability: as a deficit within the individual (aligned with the medical model of disability) or as an interaction between an individual and social structures (aligned with the social model of disability). We argue that students are better supported by instructors who intentionally choose to conceptualize disability as situated in the interaction between the individual and instructional structures and actively work to remove barriers and add supports for all students [83]. The goal of proactively designing a course with accessible practices moves us away from the idea that instructors need to know their students' diagnoses to support them [101]. Instead of saying it is the students who need to change, instructors can focus on what they can do to make their course more inclusive and supportive for all students. This shift not only makes learning more inclusive, but it also moves us away from a perspective where disability is seen as a source of inadequacy or personal fault. We have provided some recommendations in this paper for inclusive practices and strategies, and further STEM specific recommendations can be found in Refs. [47,102-106].

\section{LIMITATIONS AND RECOMMENDATIONS FOR FUTURE RESEARCH}

Because of the significant lack of research, it is critical that researchers continue to investigate the experiences of students with disabilities in STEM courses. Our findings reveal that students with disabilities experience disabling course barriers, however, this work only investigates the experiences of students with ADHD at one specific fouryear public university. Future research should investigate the experiences of students with varied diagnoses who are enrolled at other institutions. Some specific research questions which can be investigated include the effects of accommodation use on student's stress and knowledge retention, positive qualities individuals associate with their disability, and the experiences of students with disabilities in interactive learning courses including but not limited to SCALE-UP courses.

To support the dissemination of accessible practices and strategies to instructors and departments, we recommend researchers investigate ableism in physics departments and effective strategies for combating it. This research is critical as instructors and departments may not be willing to adopt accessible or inclusive practices. Previous research has identified that some postsecondary instructors are resistant to providing accommodations [28,31,34], but we are unaware of any published work that has investigated the culture of the physics community towards accessibility and disability.

\section{ACKNOWLEDGMENTS}

This work is supported by NSF DUE No. 1612009. We thank Eleazar Vasquez III and Jillian Schreffler for their feedback on the interview protocol. We especially thank an anonymous reviewer of this manuscript for their insightful and specific feedback that identified several examples of how we needed to work against our own internalized ableism in interpreting and reporting our findings and personal stance towards disability justice. 
[1] T. D. Snyder, C. de Brey, and S. A. Dillow, Digest of education statistics 2015, Report No. NCES 2016-014, 2016.

[2] A. Lee, A comparison of postsecondary science, technology, engineering, and mathematics (stem) enrollment for students with and without disabilities, Car. Develop. Except. Ind. 34, 72 (2011).

[3] E. Scanlon, J. Schreffler, W. James, E. Vasquez, and J. J. Chini, Postsecondary physics curricula and universal design for learning: Planning for diverse learners, Phys. Rev. Phys. Educ. Res. 14, 020101 (2018).

[4] N. J. Evans, E. M. Broido, K. R. Brown, and A. K. Wilke, Disability in Higher Education: A Social Justice Approach (John Wiley \& Sons, New York, 2017).

[5] M. Reed, E. Lund-Lucas, and K. O'Rourke, Standards of practice in postsecondary special needs programming: Student and administrator opinion, Can. J. High. Educ. 33, 27 (2003).

[6] Y. Leyser, S. Vogel, S. Wyland, and A. Brulle, Faculty attitudes and practices regarding students with disabilities: Two decades after implementation of section 504, J. Post. Educ. Disabil. 13, 5 (1998).

[7] Section 504 of the Rehabilitation Act of 1973, 93-112, Sec. 29 U.S.C.

[8] Americans with Disabilities Act of 1990, 101-336, Sec. 42 U.S.C.

[9] C. Thomas, Developing the social relational in the social model of disability: A theoretical agenda, in Implementing the Social Model of Disability: Theory, and Research, edited by C. Barnes and G. Mercer (The Disability Press, Leeds, 2004).

[10] J. Swain, S. French, C. Barnes, and C. Thomas, Disabling Barriers-Enabling Environments (Sage, Thousand Oaks, CA, 2013).

[11] J. I. Charlton, Nothing About Us Without Us: Disability Oppression and Empowerment (University of California Press, Berkeley, 1998).

[12] D. Goodley, Disability Studies: An Interdisciplinary Introduction (SAGE, Thousand Oaks, CA, 2016).

[13] D. Marks, Models of disability, Disabil. Rehabil. 19, 85 (1997).

[14] C. Barnes and G. Mercer, Exploring Disability (Polity, Cambridge, UK, 2010).

[15] C. Thomas, Female Forms: Experiencing and Understanding Disability (McGraw-Hill Education, London, 1999).

[16] J. Swain and S. French, Towards an affirmation model of disability, Disabil. Soc. 15, 569 (2000).

[17] W. S. Harbour, Final Report: The 2008 Biennial Ahead Survey of Disability Services and Resource Professionals in Higher Education (Association on Higher Education And Disability (AHEAD), Huntersville, NC, 2008), p. 8.

[18] National Science Foundation, Women, minorities, and persons with disabilities in science and engineering: 2019, Report No. Special Report NSF 19-304 (National Science Foundation, Washington, DC, 2019).

[19] T. D. Snyder, C. de Brey, and S. A. Dillow, Digest of education statistics 2014, Report No. NCES 2016-006 (National Center for Education Statistics, Washington, DC, 2016).
[20] A. P. Association, Diagnostic and Statistical Manual of Mental Disorders (dsm-3-r), 3rd ed. (American Psychiatric Pub., Philadelphia, PA, 1987).

[21] K. Raue and L. Lewis, Students with disabilities at degree-granting postsecondary institutions. First look, Report No. NCES 2011-018 (National Center for Education Statistics, Washington, DC, 2011).

[22] U.E.C. Unit, Equality and diversity for academics: Inclusive practice, 2013, https://www.ecu.ac.uk/wpcontent/uploads/external/e-and-d-for-academicsfactsheet-inclusive-practice.pdf.

[23] A. Duncan, Students with Disabilities Preparing for Postsecondary Education: Know your Rights and Responsibilities (2011), https://www2.ed.gov/about/offices/list/ ocr/transition.html.

[24] Individuals with Disabilities Education Act, Sec. 20 U.S.C, 2004.

[25] V. Johnston, University Students Diagnosed with Attention Deficit Hyperactivity Disorder: A Hermeneutical Phenomenological Study of Challenges and Successes (Liberty University, Lynchburg, VA, 2013).

[26] L. Mullins and M. Preyde, The lived experience of students with an invisible disability at a Canadian university, Disabil. Soc. 28, 147 (2013).

[27] N. Ofiesh, E. Moniz, and J. Bisagno, Voices of university students with ADHD about test taking: Behaviors, needs, and strategies, J. Postsec. Educ. Disabil. 28, 109 (2015).

[28] P. W. Dowrick, J. Anderson, K. Heyer, and J. Acosta, Postsecondary education across the USA: Experiences of adults with disabilities, J. Vocat. Rehabil. 22, 41 (2005).

[29] K. Q. Baker, K. Boland, and C. M. Nowik, A campus survey of faculty and student perceptions of persons with disabilities, J. Postsec. Educ. Disabil. 25, 309 (2012).

[30] D. Zhang, L. Landmark, A. Reber, H. Hsu, O.-M. Kwok, and M. Benz, University faculty knowledge, beliefs, and practices in providing reasonable accommodations to students with disabilities, Remedial Spec. Educ. 31, 276 (2010).

[31] M. Lyman, M. E. Beecher, D. Griner, M. Brooks, J. Call, and A. Jackson, What keeps students with disabilities from using accommodations in postsecondary education? A qualitative review, J. Postsec. Educ. Disabil. 29, 123 (2016).

[32] G. Mamboleo, S. Dong, S. Anderson, and A. Molder, Accommodation experience: Challenges and facilitators of requesting and implementing accommodations among college students with disabilities, J. Vocat. Rehab. 53, 43 (2020).

[33] L. Marshak, T. Van Wieren, D. R. Ferrell, L. Swiss, and C. Dugan, Exploring barriers to college student use of disability services and accommodations, J. Postsec. Educ. Disabil. 22, 151 (2010).

[34] D. Kranke, S. E. Jackson, D. A. Taylor, E. Anderson-Fye, and J. Floersch, College student disclosure of nonapparent disabilities to receive classroom accommodations, J. Postsec. Educ. Disabil. 26, 35 (2013).

[35] S. N. Perry and K. K. Franklin, I'm not the gingerbread man! Exploring the experiences of college students diagnosed with ADHD, J. Postsec. Educ. Disabil. 19, 94 (2006). 
[36] D. H. Rose, W. S. Harbour, C. S. Johnston, S. G. Daley, and L. Abarbanell, Universal design for learning in postsecondary education: Reflections on principles and their application, J. Postsec. Educ. Disabil. 19, 135 (2006).

[37] U.S. Government Accountability Office, Higher education and disability: Education needs a coordinated approach to improve its assistance to schools in supporting students (U.S. Government Accountability Office, Washington, DC, 2009).

[38] D. W. Sunal, J. Hodges, C. S. Sunal, K. W. Whitaker, L. M. Freeman, L. Edwards, R. A. Johnston, and M. Odell, Teaching science in higher education: Faculty professional development and barriers to change, School Sci. Math. 101, 246 (2001).

[39] K. Norman, D. Caseau, and G. P. Stefanich, Teaching students with disabilities in inclusive science classrooms: Survey results, Sci. Educ. 82, 127 (1998).

[40] T. S. Love, N. Kreiser, E. Camargo, M. E. Grubbs, E. J. Kim, P. L. Burge, and S. M. Culver, Stem faculty experiences with students with disabilities at a land grant institution, J. Educ. Train. Stud. 3, 27 (2014).

[41] M. A. Moriarty, Inclusive pedagogy: Teaching methodologies to reach diverse learners in science instruction, Equity Excell. Educ. 40, 252 (2007).

[42] R. D. Black, L. A. Weinberg, and M. G. Brodwin, Universal design for learning and instruction: Perspectives of students with disabilities in higher education, Except. Educ. Int. 25, 1 (2015).

[43] G. J. DuPaul, L. L. Weyandt, S. M. O'Dell, and M. Varejao, College students with ADHD: Current status and future directions, J. Atten. Disord. 13, 234 (2009).

[44] M.Z. Vickers, Accommodating College Students with Learning Disabilities: Add, ADHD, and Dyslexia (John W. Pope Center for Higher Education Policy, Raleigh, NC, 2010).

[45] C. Angell, Ø. Guttersrud, E. K. Henriksen, and A. Isnes, Physics: Frightful, but fun. Pupils' and teachers' views of physics and physics teaching, Sci. Educ. 88, 683 (2004).

[46] Building momentum towards inclusive teaching and learning (Institute of Physics, 2017), https://www.iop .org/publications/iop/2017/

page_69352.html.

[47] M. Holt, D. Gillen, S. D. Nandlall, K. Setter, P. Thorman, S. A. Kane, C. H. Miller, C. Cook, and C. Supalo, Making physics courses accessible for blind students: Strategies for course administration, class meetings, and course materials, Phys. Teach. 57, 94 (2019).

[48] J. P. Torres and E. G. Mendes, Making visual illustrations of physics accessible to blind students, Phys. Teach. 55, 398 (2017).

[49] B. Weems, A physical science course for the visually impaired, Phys. Teach. 15, 333 (1977).

[50] D. L. Hosking, The theory of critical disability theory, in Proceedings of the 4th Biennial Disability Studies Conference at Lancaster University (Lancaster University, Lancashire, England, 2008).

[51] H. Banchi and R. Bell, The many levels of inquiry, Sci. Child. 46, 26 (2008).

[52] S. L. Kerschbaum and M. Price, Centering disability in qualitative interviewing, Res. Teach. Engl 52, 98 (2017).
[53] J. Smith and M. Osborn, Interpretative Phenomenological Analysis. Qualitative Psychology: a Practical Guide to Methods (Sage, 2003).

[54] M. Freeman, The Sage Encyclopedia of Qualitative Research Methods (SAGE Publications, Thousand Oaks, CA, 2008).

[55] K. V. England, Getting personal: Reflexivity, positionality, and feminist research, Prof. Geog. 46, 80 (1994).

[56] B. Bourke, Positionality: Reflecting on the research process, Quality Control Reports 19, 1 (2014).

[57] L. Tindall, Interpretative Phenomenological Analysis: Theory, Method and Research, edited by J. A. Smith, P. Flowers, and M. Larkin (SAGE, Los Angeles, 2009).

[58] M. Q. Patton, Two decades of developments in qualitative inquiry: A personal, experiential perspective, Qual. Soc. Work 1, 261 (2002).

[59] R. J. Beichner, J. M. Saul, D. S. Abbott, J. J. Morse, R. J. Allain, S. W. Bonham, M. H. Dancy, and J. S. Risley, The student-centered activities for large enrollment undergraduate programs (scale-up) project, Res. Ref. Univ. Phys. 1, 2 (2007).

[60] R. A. Engle, J. M. Langer-Osuna, and M. McKinney de Royston, Toward a model of influence in persuasive discussions: Negotiating quality, authority, privilege, and access within a student-led argument, J. Learn. Sci. 23, 245 (2014).

[61] M. A. Davidson, Literature review: ADHD in adults: A review of the literature, J. Attent. Dis. 11, 628 (2008).

[62] R. A. Barkley, ADHD and the Nature of Self-Control (Guilford Press, New York, 1997).

[63] J. Creswell and C. Poth, Qualitative Inquiry and Research Design: Choosing Among Five Approaches (Sage Publications, Inc, Thousand Oaks, CA, 2018).

[64] J. T. Dolmage, Academic Ableism: Disability and Higher Education (University of Michigan Press, Ann Arbor, MI, 2017).

[65] A. P. Association, Diagnostic and Statistical Manual of Mental Disorders (dsm-5®), 5th ed. (American Psychiatric Pub., Philadelphia, PA, 2013).

[66] J. K. Dooling-Litfin and L. A. Rosen, Self-esteem in college students with a childhood history of attention deficit hyperactivity disorder, J. College Stud. Psychother. 11, 69 (1997).

[67] M. B. Miller, The retrospective narratives of young adults with ADHD: How self-concept development impacts psychosocial functioning, Master's thesis, Smith College, Northhampton, MA, 2017.

[68] G. G. Foster, C. R. Schmidt, and D. Sabatino, Teacher expectancies and the label "learning disabilities", J. Learn. Disabil. 9, 111 (1976).

[69] L. Barton, Disability and Youth Sport (Routledge, London, 2009), p. 51.

[70] J. A. Haegele and S. Hodge, Disability discourse: Overview and critiques of the medical and social models, Quest 68, 193 (2016).

[71] K. Gobbo and S. Shmulsky, Autistic identity development and postsecondary education, Disability Studies Quart. 36 (2016). 
[72] D. R. Dounas-Frazer, https://sites.google.com/view/ percogs/newsletters/newsletter-archive/newsletter-14november-2018.

[73] D. R. Dounas-Frazer, R. Byrd, and S. Hyater-Adams, A model for self-accountability in academia, PERCoGS Newsletter 14, 4 (2018).

[74] https://www.reneehortonphd.com/about.html.

[75] E. Gibney, How one astronomer hears the universe, Nature (London) 577, 155 (2020).

[76] P.F. Troiano, College students and learning disability: Elements of self-style, J. Coll. Student Dev. 44, 404 (2003).

[77] D. Raviv and C. A. Stone, Individual differences in the self-image of adolescents with learning disabilities: The roles of severity, time of diagnosis, and parental perceptions, J. Learn. Disabil. 24, 602 (1991).

[78] C. Henderson, College freshman with disabilities, 1999: A biennial statistical profile, in Statistical Year 1998 (Department of Education, Washington, DC, 1999).

[79] A. Baines, (un) Learning Disability: Recognizing and Changing Restrictive Views of Student Ability (Teachers College Press, New York, 2014).

[80] W. James, C. Bustamente, K. Lamons, and J. J. Chini, Beyond disability as weakness: Perspectives from students with disabilities, in Proceedings of the 2018 Physics Education Research Conference, Washington, DC, edited by A. Traxler, Y. Cao, and S. Wolf (AIP, New York, 2018), https://doi.org/10.1119/perc.2018.pr.James.

[81] G. Wolbring, Why NBIC? Why human performance enhancement?, Eur. J. Soc. Sci. Res. 21, 25 (2008).

[82] T. Hehir, Eliminating ableism in education, Harv. Educ. Rev. 72, 1 (2002).

[83] S. Baglieri and J. H. Knopf, Normalizing difference in inclusive teaching, J. Learn. Disabil. 37, 525 (2004).

[84] N. Keith and M. Frese, Effectiveness of error management training: A meta-analysis, J. Appl. Psych. 93, 59 (2008).

[85] N. Keith and M. Frese, Self-regulation in error management training: Emotion control and metacognition as mediators of performance effects, J. Appl. Psych. 90, 677 (2005).

[86] J. R. Harrison, N. Bunford, S. W. Evans, and J. S. Owens, Educational accommodations for students with behavioral challenges: A systematic review of the literature, Rev. Educ. Res. 83, 551 (2013).

[87] S. G. Sireci, S. E. Scarpati, and S. Li, Test accommodations for students with disabilities: An analysis of the interaction hypothesis, Rev. Educ. Res. 75, 457 (2005).

[88] J. K. Trammell, The impact of academic accommodations on final grades in a postsecondary setting, J. College Read. Learn. 34, 76 (2003).

[89] D. Jansen, K. Petry, S. W. Evans, I. Noens, and D. Baeyens, The implementation of extended examination duration for students with ADHD in higher education, J. Atten. Disord. 23, 1746 (2018).

[90] N. S. Ofiesh and C. A. Hughes, How much time?: A review of the literature on extended test time for postsecondary students with learning disabilities, J. Postsec. Educ. Disabil. 16, 2 (2002).

[91] D. Hammer and A. Elby, Tapping epistemological resources for learning physics, J. Learn. Sci. 12, 53 (2003).

[92] E. F. Redish, Implications of cognitive studies for teaching physics, Am. J. Phys. 62, 796 (1994).

[93] C. Bustamente, E. Scanlon, and J. J. Chini, Supporting students with ADHD in introductory physics courses: Four simple steps for instructors (to be published).

[94] C. Duquette, Experiences at university: Perceptions of students with disabilities, Can. J. High. Educ. 30, 123 (2000).

[95] K. D. Tanner, Promoting student metacognition, CBE Life Sci. Educ. 11, 113 (2012).

[96] M. Kryjevskaia, M. R. Stetzer, and N. Grosz, Answer first: Applying the heuristic-analytic theory of reasoning to examine student intuitive thinking in the context of physics, Phys. Rev. Phys. Educ. Res. 10, 020109 (2014).

[97] M. Kryjevskaia, in Upgrading Physics Education to Meet the Needs of Society (Springer, New York, 2019), p. 181.

[98] S. Bailin, Critical thinking and science education, Sci. Educ. 11, 361 (2002).

[99] D. T. Tiruneh, M. De Cock, A. G. Weldeslassie, J. Elen, and R. Janssen, Measuring critical thinking in physics: Development and validation of a critical thinking test in electricity and magnetism, Int. J. Sci. Math. Educ. 15, 663 (2017).

[100] S. Kanim and X. C. Cid, The demographics of physics education research, Phys. Rev. Phys. Educ. Res. 16, 020106 (2020).

[101] N. Matthews, Teaching the "invisible" disabled students in the classroom: Disclosure, inclusion and the social model of disability, Teach. Higher Educ. 14, 229 (2009).

[102] E. Scanlon and J. J. Chini, A Framework for Conceptualizing Dimensions of Ability, in Proceedings of the 2018 Physics Education Research Conference, Washington, DC, edited by A. Traxler, Y. Cao, and S. Wolf (AIP, New York, 2018), https://doi.org/10.1119/perc.2018.pr.Scanlon.

[103] W. James, J. Cooney, E. Vasquez, III., J. Schreffler, and J. J. Chini, Using universal design for learning to support students with disabilities in a scale-up physics course, Phys. Teach. (to be published).

[104] L. Amanda, E. Scanlon, and J. J. Chini, Resources for supporting students with and without disabilities in your physics courses, Phys. Teach. (to be published).

[105] S. Ahmed, Access for all: A guide to disability good practice for university physics departments, 2008, https:// www.iop.org/publications/iop/2008/file_42866.pdf. 